Table 2

(B): Observed frequencies. for an individual S, of responses placed in categories according to whether $I$ and $P$ responses are right or wrong. (D). (E), and (F): Frequencies expected under HIP, HPI, and HC, respectively

\begin{tabular}{|c|c|c|c|c|c|c|c|c|}
\hline $\begin{array}{rll} & \text { P } & \text { Px } \\
\text { IN } & a & b \\
\text { Ix } & c & d \\
\end{array}$ & & $\begin{array}{l}\mathrm{PV} \\
\mathrm{IV} \text { a } \\
\mathrm{I} \times \mathrm{c} \\
\end{array}$ & $\begin{array}{l}\text { Px } \\
e \\
e \\
\end{array}$ & $\begin{array}{r}P J \\
I J a \\
I \times f \\
\end{array}$ & $\begin{array}{l}\mathrm{Px} \\
\mathrm{b} \\
\mathrm{f} \\
\end{array}$ & $\begin{array}{l}\text { PJ } \\
I J a \\
I \times g \\
\end{array}$ & $\begin{array}{l}P \times \\
g \\
g\end{array}$ & \\
\hline (B) & 200 & & (D) 200 & & (E) 200 & & (F) & 200 \\
\hline
\end{tabular}

and HPI is equivalent to acceptance of $\mathrm{HC}$, and the entry in Column F shows that HC does indeed provide a satisfactory fit to the data.

The probability values for the eight individual $S s$ under each of the four hypotheses confirm these general conclusions: All but two of the eight values in Column $C$ of Table 1 are less than 0.05 ; all but two of the 16 values in Columns $D$ and $E$ are greater than 0.05 ; and all eight values in Column $F$ are greater than 0.05 .

Our results, then, indicate that when items are presented tachistoscopically in a two-dimensional display, and when recall is from short-term memory (AIS) rather than from a peripheral sensory store (VIS), the hypothesis that the position of an item in the display and the identity of the item are stored as a unit and forgotten or retained together fits the data much better than any of the other three hypotheses considered.

\section{REFERENCES}

SPERLING, G. A model for visual memory tasks. Human Factors, 1963, 5, 19-31.

SPERLING, G. Successive approximations to a model for short-term memory. In A. F. Sanders (Ed.), Attention and performence. Amsterdam: North Holland Publishing Co., 1967. NOTE

1. Now at the Institute of Experimental Psychology, Oxford.

\title{
Visual temporal discrimination: A point of order
}

\section{CARL E. SHERRICK, Princeton University Princeton, N.J. 08540}

The discrepancies in results between no experiments on the visual detection of temporal order are discussed, and it is suggested that the differences arise in great part from the definition of interstimulus interval. The controversy resulting from the misunderstanding is reviewed briefly but optimistically.

Recently there has appeared a series of papers concerned with the question of the visual perception of temporal order under conditions of dichoptic viewing (Robinson, 1967a, b, 1968; Thor, 1967, 1968). In brief, these authors have disagreed on the interpretation of findings of Robinson (1967a). The results of Hirsh \& Sherrick (1961), that flashes must be separated by about $20 \mathrm{msec}$ for correct order to be judged, were replicated successfully by Robinson when he adopted their binocular viewing conditions. Robinson found in addition that under haploscopic viewing conditions (dichoptic observation), “. . all Ss correctly perceived presentation order 100 percent of the time at all intervals except 0 [1967a, p. 1264]." Thor (1967) was unable to replicate Robinson's results, but in a later publication (1968) reported that one $O$ improved his performance in detecting order at the 0 -msec interval between stimuli by adopting a viewing strategy in which ". . . the images of triangle and square appeared in slightly different locations in visual space ... the $S$ attended to apparent movement, and the direction of apparent movement served as the cue to order of presentation [1968, p. 41]." Robinson (1968) has reiterated his view that the important point concerns central versus peripheral processing, and that, "...the basic research question is one of central temporal resolution capabilities ... [1968, p. 247]."

I find myself in agreement with Dr. Robinson, and indeed Hirsh and I affirmed his point of view in the original paper, when we stated that there seems to be," . . some kind of time-organizing system that is both independent of and central to the sensory mechanisms [1961, p. 431]." There is one small technical point that needs clearing up, and, I believe, will lend perspective to the controversy between Robinson and Thor.

In the experiments of Hirsh and Sherrick the flash durations were $5 \mathrm{msec}$, and the interval of the limen for order (ca. $20 \mathrm{msec}$ ) was taken as the time from the onset of the first stimulus to the onset of the second. Robinson's (1967a) flash durations were $10 \mathrm{msec}$, and his interstimulus intervals $(0$. $5,10,20 \mathrm{msec}$, etc.) should be read, in Hirsh and Sherrick's terms, as 10, 15,20.30 msec, etc. Robinson, in order words, was employing the traditional "dark interval" of visual research for his values. (I am indebted to Dr. Richard Gilson for pointing out this discrepancy.) The differences in results are therefore not as large as they first seemed (Robinson's limen ca. $15 \mathrm{msec}$ vs Hirsh and Sherrick's limen ca. $20 \mathrm{msec}$ ). If one assumes a standard error of estimate of 3 to $6 \mathrm{msec}$ for the conditions and number of $\mathrm{Os}$ involved, the differences may not even be significant for the series of experiments under discussion, including the binocular results of Robinson, which now appear to be $10 \mathrm{msec}$ longer than the limen obtained by Hirsh and Sherrick.

The foregoing is not meant to imply that Robinson and Thor have been tilting over a dubious cause. On the contrary, they have by their research techniques opened new avenues of inquiry that should be followed. It is certainly true that such parameters of the stimulus as duration of flash (Thor \& Spitz, 1968), retinal locus (Rutschmann, 1966; Robinson, 1967; Thor, 1967, 1968), and form quality of the image (Robinson, 1967; Thor \& Spitz, 1968) may affect the limen for order. In addition, the $O$ 's learning of specific viewing strategies, which can reduce the limen for order by significant amounts (Hirsh \& Fraisse, 1964; Thor, 1968), deserves further research in its own right; sensory psychology has too long assumed that the training preceding testing is a vague learning process that does not vary over Os, modalities, perceptual dimensions, or experimental conditions. It is time that the set we call a "control variable" be examined for possible plurality of membership, and we are indebted to Drs. Robinson and Thor for underscoring the need.

\section{REFERENCES}

HIRSH, I. J., \& FRAISSE, P. Simultanéité et succession de stimuli hétérogenes. Année psychologique, 1964, 64, 1-19.

HIRSH, I. J., \& SHERRICK, C. E., JR. Percived order in different sense modalities. Joumal of Experimental Psychology, 1961, 62, 423432.

ROBINSON, D. N. Visual discrimination of temporal order. Science, 1967a, 156, 1263-1264.

ROBINSON, D. N. Dichoptic viewing and temporal discrimination: An attempted replication. Science, 1967b, 158, 1704-1705.

ROBINSON, D. N. Assessments of temporal discrimination in vision. Psychonomic Science, 1968, 13, 247.

RUTSCHMANN, R. Perception of temporal order and relative visual latency. Science, 1966, 152. 1099-1101.

THOR, D. H. Dichoptic viewing and temporal discrimination: An attempted replication. Stience, 1967, 158, 1704-1705.

THOR. D. H. Observer strategies in dichoptic view ing of successive stimuli. Psychonomic Science. 1968, 12,41-42.

THOR. D. H., \& SPITZ, H. H. Temporal discrimination as a function of total presentation time. Psychonomic Science, 1968, 13 , 291-292. 